\title{
Water Vapor Measurements by Raman Lidar During the ARM 1997 Water Vapor Intensive Observation Period
}

\author{
D.D. Turner', D.N. Whiteman ${ }^{2}$, K.D. Evans ${ }^{3}$, S.H. Melfi, \\ J.E.M. Goldsmith ${ }^{5}$, and G.K. Schwemmer ${ }^{6}$ \\ ${ }^{1}$ Pacific Northwest National Laboratory, P.O. Box 999, MS K7-28, Richland, WA 99352 \\ 509-375-2590, 509-375-3641 (fax), dave.turner@pnl.gov \\ ${ }^{2}$ NASA/Goddard Space Flight Center, Code 924, Greenbelt, MD 20771 \\ 301-286-3115, 301-286-1761 (fax), david.whiteman@gsfc.nasa.gov \\ ${ }^{3}$ University of Maryland Baltimore County, NASA/GSFC, Code 912, Greenbelt, MD 20771 \\ 301-286-9526, 301-286-1762 (fax), evans@agnes.gsfc.gov \\ ${ }^{4}$ University of Maryland Baltimore County, Baltimore, MD 21228 \\ 410-455-2186, 410-455-1291 (fax), melfi@umbc.edu \\ ${ }^{5}$ Sandia National Laboratories, P.O. Box 969, MS 9409, Livermore, CA 94551 \\ 510-294-2432, 510-294-3870 (fax), jgold@ca.sandia.gov \\ ${ }^{6}$ NASA/Goddard Space Flight Center, Code 912, Greenbelt, MD 20771 \\ 301-286-5768, 301-286-1761 (fax), geary@virl.gsfc.nasa.gov
}

\section{INTRODUCTION}

Water vapor is the most important greenhouse gas in the atmosphere, as it is the most active infrared absorber and emitter of radiation, and it also plays an important role in energy transport and cloud formation. Accurate, high resolution measurements of this variable are critical in order to improve our understanding of these processes and thus our ability to model them. Because of the importance of water vapor, the Department of Energy's Atmospheric Radiation Measurement (ARM) program initiated a series of three intensive operating periods (IOPs) at its Cloud and Radiation Testbed (CART) site in northern Oklahoma. The goal of these IOPs is to improve and validate the state-ofthe-art capabilities in measuring water vapor. To date, two of the planned three IOPs have occurred: the first was in September of 1996, with an emphasis on the lowest kilometer, while the second was conducted from September - October 1997 with a focus on both the upper troposphere and lowest kilometer.

The ARM CART site is the home of several different water vapor measurement systems. These systems include a Raman lidar, a microwave radiometer, a radiosonde launch site, and an instrumented tower. During these IOPs, additional instrumentation was brought to the site to augment the normal measurements in the attempt to characterize the CART instruments and to address the need to improve water vapor measurement capabilities. Some of the instruments brought to the CART site include a scanning Raman lidar system from NASA/GSFC, additional microwave radiometers from NOAA/ETL, a chilled mirror that was flown on a tethersonde and kite system, and dewpoint hygrometer instruments flown on the North Dakota
Citation. This paper will focus on the Raman lidar intercomparisons from the second IOP.

\section{LIDAR SYSTEM DESCRIPTIONS AND CALIBRATION}

The CART Raman lidar (CARL) is an autonomous system that is permanently deployed at the site. It uses a tripled Nd:YAG laser $(355 \mathrm{~nm})$, with an average power of approximately $12 \mathrm{~W}$ and a repetition rate of $30 \mathrm{~Hz}$. A $61 \mathrm{~cm}$ telescope directs the collected light into the detection optics, where the beam is split into two channels which have different fields-of-view. The wide field-of-view (WFOV) channel has a aperture of $2 \mathrm{mrad}$ while the narrow field-ofview (NFOV) is $0.3 \mathrm{mrad}$. The WFOV channels are better suited to profile in the near field (up to approximately 1.5 $\mathrm{km}$ at night, lower during the day) as they admit more light than the NFOV channels at these low altitudes. After the field stops, the light is separated into three wavelengths (elastic backscatter and the two inelastic wavelengths associated with water vapor and nitrogen Raman backscatter) by dichroic mirrors. Narrow bandpass $(0.3 \mathrm{~nm})$ interference filters select only the desired wavelength, and the signal are detected using photon counting in approximately 0.25 microsecond bins ( $39 \mathrm{~m}$ resolution). The narrow field of view coupled with narrow interference filters give the CARL system excellent nighttime and daytime abilities. Further details are given in [1].

The NASA/Goddard Space Flight Center scanning Raman lidar (SRL) was developed in the early 1990's, and was first deployed in the fall of 1991 [2]. This system uses a XeF excimer laser operating at $351 \mathrm{~nm}$. Its average power is 24 W with a repetition rate of $400 \mathrm{~Hz}$. It is aligned with a 76 $\mathrm{cm}$ telescope, and the collected light is separated into two 


\section{DISCLAIMER}

This report was prepared as an account of work sponsored by an agency of the United States Government. Neither the United States Government nor any agency thereof, nor any of their employees, makes any warranty, express or implied, or assumes any legal liability or responsibility for the accuracy, completeness, or usefulness of any information, apparatus, product, or process disclosed, or represents that its use would not infringe privately owned rights. Reference herein to any specific commercial product, process, or service by trade name, trademark, manufacturer, or otherwise does not necessarily constitute or imply its endorsement, recommendation, or favoring by the United States Government or any agency thereof. The views and opinions of authors expressed herein do not necessarily state or refiect those of the United States Government or any agency thereof. 
channels, each detecting 4 wavelengths (elastic backscatter, water vapor, nitrogen, and oxygen Raman backscatter). Photon counting data are recorded from each of the PMTs in 0.5 microsecond bins, with a resulting range resolution of 75 $\mathrm{m}$. A large scan mirror allows profiles to be acquired at any angle in a single scan plane, and thus allows for improved measurements at low altitudes for comparisons with tower and surface based instruments. The SRL was optimized for nighttime operation.

Corrections for pulse pile-up (system dead-time), detector overlap, and differential attenuation at the different wavelengths are accounted for in both lidar systems by techniques outlined in [1-3]. If these corrections are adequately specified, the resultant ratios of the water vapor and nitrogen signals are proportional to the water vapor mixing ratio. To calibrate these profiles, height independent scale factors are derived to force the integrated precipitable water vapor measured by the two Raman lidars to agree with that measured by the CART microwave radiometer. A single calibration scale factor was used for each lidar dataset for the entire IOP.

\section{MIXING RATIO COMPARISONS}

The side-by-side deployment of the SRL and CARL during the IOP provided an opportunity to compare the two

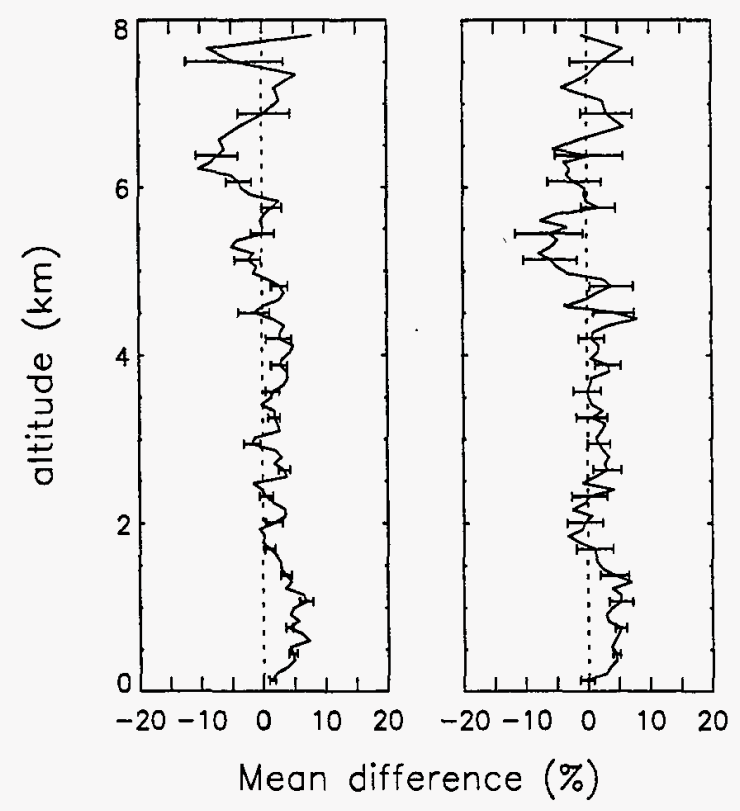

Figure 1. Mean mixing ratio difference profiles, in percent, between the CARL and SRL (left, 162 cases) and the CARL and radiosondes (right, 32 cases) for the 1997 IOP. The error bars denote one standard deviation of the mean. lidar systems' water vapor mixing ratio measurements as a function of height during all times that the lidars were operating to determine if there were any systematic differences between the two lidars. Selecting only the nighttime clear sky cases during the IOP, coincident 10 minute mixing ratio profiles were generated and then compared. The mean relative difference of 162 intercomparison cases is given in the left panel of Fig. 1. This mean profile demonstrates excellent overall agreement between the two lidar systems, with a small (approximately $5 \%$ ) difference in the lowest $1.5 \mathrm{~km}$.

Comparing 30 minute averages from the CARL system to the Vaisala radiosondes launched during the IOP (the launch site is within $80 \mathrm{~m}$ of the lidar) at night in a similar manner also demonstrates that the CARL system appears to be moister in the lowest layer of the atmosphere. This is shown in the right panel of Fig 1. This apparent moist bias of the CARL system is associated with the WFOV channels, which were calibrated to create the best agreement with the NFOV channels from 1.3-1.6 km. Small errors in the determination of the overlap correction and/or pulse-pileup correction in the NFOV channels could affect shape of the NFOV profile in this range, and thus affect the calibration of the WFOV channels [3]. Further study into these differences is continuing.

Water vapor measurements in the upper troposphere are particularly difficult due to the very dry and cold conditions encountered there. Although moisture decreases rapidly with altitude, upper tropospheric moisture still plays a large role in the formation of clouds and radiative transfer, and hence

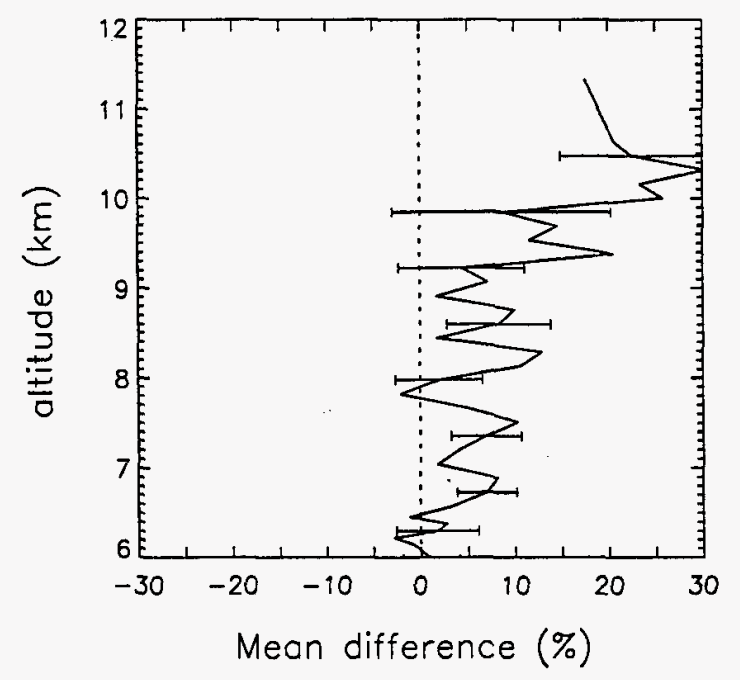

Figure 2. Mean mixing ratio difference profiles, in percent, between the CARL and radiosondes ( 32 cases) in the upper troposphere. The lidar data are 30 minute averages after the radiosonde launch. The error bars denote one standard deviation of the mean. 
this IOP placed special emphasis on these measurements. Comparisons of 30 minute averages from the CARL system with the radiosondes launched during the night at the CART site during the IOP reveals a significant difference between the two measurement techniques. Fig. 2 shows the mean difference in mixing ratio, expressed as a percent, where the relationship used is (CARL - sonde) / CARL. The error bars in the figure denote the standard deviation of the mean difference. For these comparisons, the CARL data was not used if the signal-to-noise ratio was less than 4.0. The SRL agrees quite well with the CARL data, with the SRL slightly moister at these altitudes. The trend shown here could be due to a small amount of signal-induced noise in the lidar measurements and/or a dry bias in the radiosondes. Other investigators have reported dry biases in radiosonde data in the upper troposphere [4].

During this IOP, a cryogenic dewpoint hygrometer was flown on the North Dakota Citation to gather additional insitu measurements of water vapor. The water vapor field on the morning of 1 October, 1997, (1-5 UTC) was fairly stationary, which helped to facilitate the intercomparisons between the lidars, radiosondes and the Citation data. The radiosonde was launched at 2:30 UTC, reaching the upper troposphere at approximately the same time the Citation

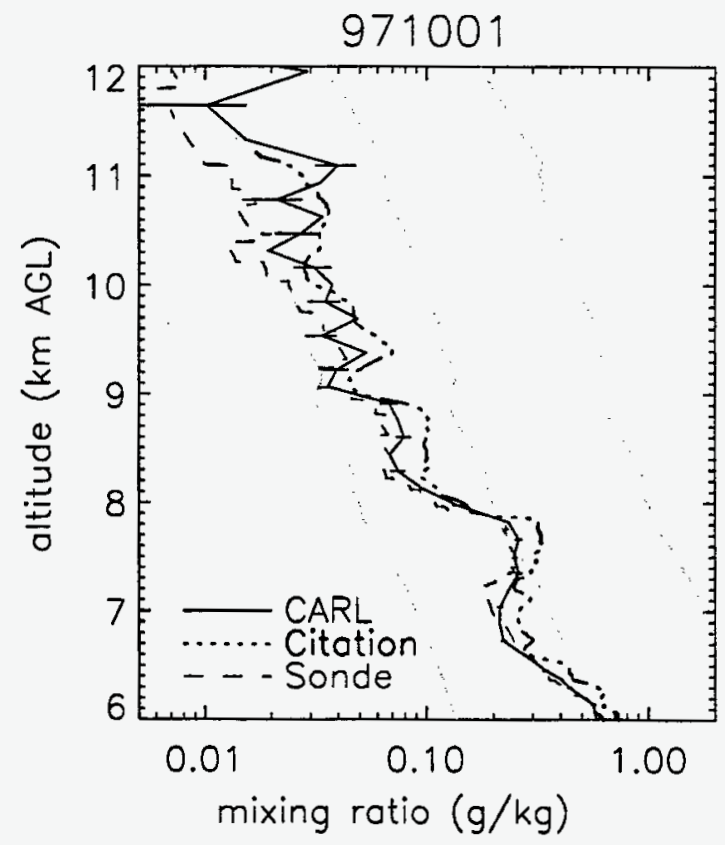

Figure 3. CARL 3-hour profile compared to the Citation frostpoint hygrometer during descent and to the Vaisala radiosonde. These data are from 1 October, 1997 1:30 - 4:30 UTC. Also shown (as light gray lines) are the 5\%, 20\%, and $100 \%$ saturation profiles derived using the temperature and pressure profiles from the radiosonde. The height resolution of the lidar data is $156 \mathrm{~m}$ up to $9.5 \mathrm{~km}, 312$ meters above $9.5 \mathrm{~km}$. started its descent. These profiles were compared to 3 hour averaged profiles from both lidars (the SRL profile is not shown, but is very similar to the CARL profile) in Fig. 3 . This comparison indeed shows the radiosonde to be drier than the CARL, which agrees fairly well with the Citation data between $9.5-11 \mathrm{~km}$, although the aircraft data are moister below $9.5 \mathrm{~km}$.

\section{CONCLUSION}

Detailed comparisons of mixing ratio profiles from two Raman lidars, radiosondes, and a dewpoint hygrometer flown on an aircraft have been presented. These results highlight the excellent agreement between the lidars and radiosondes, which is quite remarkable given that the lidars were both calibrated to a microwave radiometer. They also indicated that the CARL system has a possible wet bias (on the order of $4-5 \%$ ) in the lowest $1.5 \mathrm{~km}$, and that more research is needed to resolve differences in the upper tropospheric water vapor measurements.

\section{REFERENCES}

[1] J.E.M. Goldsmith, F.H. Blair, S.E. Bisson, and D.D. Turner, "Turn-key Raman lidar for profiling atmospheric water vapor, clouds, and aerosols," Appl. Opt., in press.

[2] D.N. Whiteman, S.H. Melfi, and R.A. Ferrare, "Raman lidar system for the measurement of water vapor and aerosols in the Earth's atmosphere," Appl. Opt., vol. 31, pp. 3068-3082, 1992.

[3] D.D. Turner and J.E.M. Goldsmith, "24 hour Raman lidar water vapor measurements during the Atmospheric Radiation Measurement Program's 1996 and 1997 water vapor intensive observation periods," unpublished.

[4] B.J. Soden, S.A. Ackerman, D.O'C. Starr, S.H. Melfi, and R.A. Ferrare, "Comparison of upper tropospheric water vapor from GOES, Raman lidar, and cross-chain loran atmospheric sounding system measurements," J. Geophys. Res., vol. 99, pp. 21005-21016. 


\section{M98052867}

||||||||||||||||||||||||||||||||||||||||||||||||||||||||||||||

Report Number (14) $\frac{S A N D--98-8537 C}{\text { CONF-980715- }}$

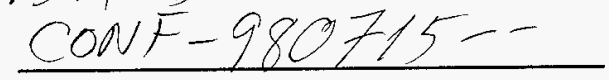

Publ. Date (11)

Sponsor Code (18) DOE/ER, XF

UC Category (19) $1 \mathrm{C}-406, D O E / E R$ 